\title{
Bioactive Metabolites Produced by Fungi Cultures
}

\author{
L.M. Levy ${ }^{1}$, G. M. Cabrera ${ }^{1}$, Jorge E. Wright ${ }^{2}$ and A. M. Seldes ${ }^{1}$ \\ ${ }^{1}$ Depto de Química Orgánica - Facultad de Ciencias Exactas y Naturales - Universidad de Buenos Ai- \\ res - Ciudad Universitaria - Pab. II - (1428) Buenos Aires, Argentina \\ ${ }^{2}$ Depto de Biología - Facultad de Ciencias Exactas y Naturales - Universidad de Buenos Aires - Ciudad \\ Universitaria - Pab. II - (1428) Buenos Aires, Argentina \\ E-mail: gabyc@qo.fcen.uba.ar
}

\begin{abstract}
A screening of metabolites guided by antimicrobial and citotoxic bioassays was conducted with several fungi. The bioactive compounds were isolated and identified from the active extracts.
\end{abstract}

\section{Introduction}

As fungi are increasingly being investigated for their production of biologically active secondary metabolites since they are known to produce compounds with a variety of biological activities, we undertook a screening program for antifungal and antibacterial fungal metabolites.

\section{Results and Discussion}

Different strains of fungi were cultured in small scale. Extracts of the mycelium and medium were made. The extracts were bioassayed. Antibiotic activity against Escherichia coli, Bacillus subtilis, Staphylococcus aureus and Candida albicans, and cytotoxicity against different tumor cell lines were assayed. The fungi with active extracts were cultured in a greater scale. From a first collection of ten fungi, two were selected because of their antibiotic activity against Gram positive bacteria. These strains were Bjerkandera adusta and Coriolellus malicola.

The extracts of these cultures were fractionated by vacuum chromatography and then the active compounds were separated and purified by preparative thin layer chromatography or HPLC. The pure compounds were identified by spectroscopic methods, 1D and 2D NMR and Mass Spectrometry.

The following compounds were isolated and identified from the extract of the culture of Bjerkandera adusta. The halogenated compounds are responsible for the antibiotic activity. 


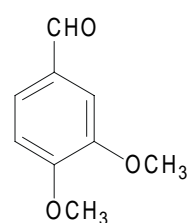<smiles>COc1ccc(C=O)cc1Cl</smiles><smiles>COc1c(Cl)cc(C=O)cc1Cl</smiles><smiles>COc1c(Cl)cc(C(O)C(C)O)cc1Cl</smiles><smiles>COc1ccc(C(O)C(C)O)cc1Cl</smiles><smiles>O=Cc1c[nH]c2ccccc12</smiles>

The bioactive compounds isolated and identified from Coriolellus malicola were known triterpene acids.

\section{Experimental}

Most of the fungi were culture in malt extract medium at $25^{\circ} \mathrm{C}$. For the culture of $B$. adusta a special medium was employed [1].

Acknowledments: We thank LANAIS-EMAR (CONICET-FCEN, UBA) for the mass spectra, UMYMFOR (CONICET-FCEN, UBA) for the NMR spectra, Dras Bals de Kier Hoffe and Puricelli (Instituto Roffo) for the cytotoxicity assays and CONICET, Fundación Antorchas and Universidad de Buenos Aires for their partial financial support.

\section{References and Notes}

1. Spinnler, H.-E.; de Jong, E.; Mauvais, G.; Semon, E., le Quere, J.-L. Appl. Microbiol. Biotechnol. 1994, 42, 212.

2. Lauritsen, F. R.; Lunding, A. Enzyme and Microbial Technology 1998, 22, 459. 